\title{
High-grading effects on Scots pine volume and basal area in pure stands in northern Spain
}

\author{
Felipe Bravo ${ }^{\mathrm{a} *}$ and Gregorio Montero ${ }^{\mathrm{b}}$ \\ ${ }^{\text {a }}$ Dept. de Producción Vegetal y Silvopascicultura, University of Valladolid, Campus at Palencia, \\ Avda. de Madrid, 44, 34004 Palencia, Spain \\ b CIFOR-INIA, PO Box 8011, 28080 Madrid, Spain
}

(Received 24 January 2002; accepted 25 March 2002)

\begin{abstract}
A yield model for formerly high-graded Scots pine stands in a transitional climatic area in northern Spain has been developed. High grading practices were used broadly during the last decades. In the past years, the silvicultural system has switched to a conventional even-aged system. A modeling approach is used to understand the effects of high-grading on basal area and dominant height. The equations are calibrated to be used in non high-graded stands and in previously high-graded stands when the silvicultural practices are switched. Dominant height and linear models were used to calibrate the original multiplicative model. With these models the effect of high-grading practices upon forest yield was studied. Standing volume decreased due to high-grading over $26 \%$ as the rotation age increased in a medium productivity class. The total volume reduction at rotation age was $18 \%$.
\end{abstract}

Pinus sylvestris / high-grading / yield / Scots pine / Spain

Résumé - Effets du système de coupe à la dimension sur le volume et la surface terrière de peuplements de Pin sylvestre au nord de l'Espagne. On a mis au point un modèle de croissance des peuplements de Pin sylvestre soumis auparavant à ce système dans une région climatique de transition située au nord de l'Espagne. Ce type de sylviculture, consistant à récolter systématiquement les arbres de gros diamètre, a été courant au cours des dernières décennies. Depuis quelques années on abandonne cette méthode pour adopter le traitement en futaie régulière. On a fait appel à l'approche modélisation pour estimer les effets du système de coupe à la dimension sur la surface terrière et la hauteur dominante. Les équations ont été étalonnées de manière à pouvoir être utilisées aussi bien pour les peuplements n'ayant pas été soumis à ce système de coupe que pour ceux qui, l'ayant subi dans le passé, ont bénéficié d'un nouveau traitement. Le modèle multiplicatif d'origine a été calibré selon des modèles linéaires en utilisant la hauteur dominante. On a pu estimer, grâce à ces modèles, l'effet des coupes à la dimension sur la production. On enregistre alors une réduction du volume sur pied de $26 \%$ dans le cas d'une résolution longue et pour une classe de production moyenne. La réduction du volume total produit en fin de révolution s'élève à $18 \%$.

Pinus sylvestris / coupe à la dimension / rendement / Pin sylvestre / Espagne

\section{INTRODUCTION}

High-grading is a traditional harvesting practice that overexploits forests by removing only the dominant trees. In northern Spain, high-grading is usually defined as cutting all commercial trees equal to or larger than $40 \mathrm{~cm}$ in diameter, and leaving all non-commercial trees. Although high-grading produces high short-term returns, its negative effects on soil rent, depletion of biological diversity and very poor stand structure [10] have led to its discontinued use as a forest management practice. Dominant height, size-density relationships, diameter distribution and other stand characteristics are affected by high-grading. High-grading reduces stand dominant height and quadratic mean diameter because the biggest trees are harvested. High-grading promotes small gaps that are occupied by young trees and results in a prevalence of codom- inant and suppressed trees, so the resulting diameter distribution ranges from normal to reverse-J including bimodal shapes. Upon release the understory often exhibits a lag in height and diameter growth [12]. By using high-grading, a high structural diversity can be achieved, but must be considered that a reduction of over a 10 percent in diameter growth rate must be expected in Mediterranean pine stands [1]. Using data sets from high-graded stands to fit growth and yield models, the growth estimation underestimates the actual values of non-high-graded stands. A possible solution is to calibrate the model using independent non high-graded data sets. On the other hand, there are taper differences between dominant and codominant trees. In general, dominant trees have more diameter growth and taper at a given height, resulting in more volume than codominant trees of the same height [9]. 
In Scots pine stands, high-grading practices have been discontinued some years ago but the effects of high-grading on forest stand structure are still important. Scots pine (Pinus sylvestris L.) is one of the most wide spread species around the world, dominating forest landscapes from boreal areas to Mediterranean mountains in Europe. Local and regional research is needed in order to define sustainable forest management in these forests. Silvicultural studies of Scots pine stands in the transitional area in the Southern limit of its distribution are scarce in the relevant literature. The objective of this study is to explore the influence of high-grading practices upon forest yield. To accomplish this objective, a yield model was fitted and calibrated and the behavior of the model with and without high-grading was studied. Results from this empirical study can serve to better understand the effects of high grading.

\section{MATERIALS AND METHODS}

\subsection{Study area}

The High Ebro basin (northern Spain) was selected as the study area because high-grading has had a strong influence on forest stands in this area. The High Ebro basin is a transitional area for Scots pine in northern Spain situated between 700 and $900 \mathrm{~m}$ a.s.l. The climate ranges from the Mediterranean to the Atlantic type, with an annual rainfall of about $800 \mathrm{~mm}$ (approximately 15 percent in summer) and an average temperature of $11.2^{\circ} \mathrm{C}$. In general, the area does not suffer from pronounced drought or severe frost but these stresses can occasionally occur. Typical interannual variation of temperature and rainfall of the Mediterranean climate is moderated by the Atlantic influence. Soils are mostly calcarous cambisols involving luvisols in humid sites. While in boreal Scots pine stands nutrient levels are the key to determine site index, in this transitional area soil texture is the driving factor in site productivity estimation [2]. Pinus sylvestris L. occupies the overstory and the remaining vegetative community is dominated by a mixture of Quercus faginea Lamk, Fagus sylvatica L., Quercus ilex L., Calluna vulgaris (L.) Hull, Erica sp, Ulex sp and Pteridium aquilinum (L.) Kuch. Beech (Fagus sylvatica) is the most common invading species on the most humid high-graded Scots pine stands in the study area. Understory species limit Scots pine natural regeneration [4] by competition for water, especially during dry years. This indicates the importance of water stress in these stands.

\subsection{Data}

Data to develop the model came from the Second Spanish Forest Inventory [5]. The plots of the Second Spanish Forest Inventory (2SFI) are systematically distributed using a grid of one square kilometer. Each plot consists of four concentric subplots with radius 5, 10,15 and $25 \mathrm{~m}$. For these subplots, the minimum diameter recorded is $7.5,12.5,22.5$ and $42.5 \mathrm{~cm}$, respectively. In order to expand the data to the hectare the following expansion factors have been used, 127.32, 31.83, 14.16 and 5.09 for each minimum diameter, respectively.

At plot establishment, the following data were recorded for every sample tree: species, diameter at $1.3 \mathrm{~m}(\mathrm{DBH})$ to the nearest millimeter, total height to the nearest quarter meter, and the distance and azimuth from the plot center in meters and degrees, respectively. Diameters were measured with a caliper in two perpendicular directions.

After defining the study area, 75 plots were chosen from the 2SFI database which met the following criteria: (1) at least $70 \%$ of the basal area in Scots pine, (2) dominant height above $6 \mathrm{~m}$, and (3) basal area above 15 squared meters per ha. During the past decades, highgrading practice had been used extensively throughout the study aera so the plots represent mostly high-graded stands. In stands that were high-graded a few decades ago, it is difficult to find clues of highgrading, but its effects are still important. In figure 1, we can observe some diameter distribution from high-graded stands in our study area. The plots cover a wide range of dominant height and basal area (dominant height ranging from 6.3 to $23.7 \mathrm{~m}$ and basal area ranging from 15.3 to $60.2 \mathrm{~m}^{2}$ per hectare). Site index was determined using the method developed by Bravo and Montero [2]. Site index classes (dominant height in meters at 100 years old) of 2SFI plots in the study area were 14, 17, 20 and $23 \mathrm{~m}$.

Data from permanent plots and thinning experiments under traditional even-aged silviculture were used to study the behavior and calibrate the fitted model. Three permanent plots $(600,1000$ and $2500 \mathrm{~m}^{2}$ ) were used to study the behavior of the model. These permanent plots were installed in 1964 to study growth and yield under even-aged management practices, and they were remeasured every five years until 1979. DBH was recorded for each tree and total height was measured on the 10 trees with largest DBH's and on a random sample of 30 additional trees. In fifteen sample trees from these permanent plots, the age, total and merchantable height, and the diameter outside bark at $50 \mathrm{~cm}$ intervals up the stem were recorded. Additionally, data from two thinning experiments were used to calibrate the model. The thinning experiments were installed in the Iberica Range in 1968 and remeasured every five years until 1998. In both cases, the experimental design was a complete randomized block design. Using classical Assmann's classification, in one of the thinning experiments four treatments were tested: (1) no treatment (grade A), (2) weak thinning (grade C), (3) moderate thinning from below (grade D), and (4) heavy thinning from below (grade E). Only three treatments (A, C and $\mathrm{D}$ ) were tested in the other thinning experiment. The experiment started when the stand was 41 years old in the first experiment site and when the stand was 50 years old on the second one. Site index ranged from 20 to 23 in the first forest experiment and between 17 and 20 in the second according to Rojo and Montero [18] and Bravo and Montero [2] site index curves. A complete description of these thinning experiments can be found in Río [16] and in Río et al. [17]. Eighty-two observations have been used from the thinning experiments. These two data sets (permanent plots and thinning experiment) were not used to fit the model but to explore its behavior and calibrate it, respectively.

\subsection{Methods}

\subsubsection{Model structure}

The data available for modeling determine both the type of model that can be developed and the precision of the predictions from the model. The 2SFI data have the following characteristics: (1) presently, we have just one measurement, (2) the plot design used four nested subplots based upon DBH and, therefore, the density and the diameter distribution per hectare must be computed from the expansion factors for each subplot, and (3) increment cores were not extracted from each tree. As a result of these limitations, a whole stand yield model approach was chosen.

Multiplicative models are based on Mitscherlich's law or the law of limiting factors. These types of models have been used previously to elaborate whole stand models for Picea abies [3] and Pinus sylvestris [14], to estimate diameter distribution parameter dynamics under different planting densities [9] and to fit crown relations in conifer species [10]. The general form of the multiplicative model is:

$$
Y=\beta_{0} \times X_{1}^{\beta 1} \times X_{2}^{\beta 2} \times \ldots \ldots . X_{\mathrm{n}}^{\beta \mathrm{n}}
$$


where $Y$ is the dependent variable, $X_{\mathrm{i}}$ is the ith independent variable and $\beta_{0}, \beta_{1}, \beta_{\mathrm{n}}$ are parameters to be estimated.

The dependent variables used in this study were mean quadratic diameter $(\mathrm{dg})$, basal area $(\mathrm{G})$ and total volume $(\mathrm{V})$ of Scots pine. The independent variables were chosen after a correlation study that rejected the variables that were not significant at $P=0.001$. The final independent variables used were number of Scots pine stems per ha $(\mathrm{N})$, dominant height $\left(\mathrm{H}_{0}\right)$ and the stand density index (SDI). Age was rejected because it is difficult to determine stand age in a mixed structured high graded forest. In addition, site index (SI) was not used because of its lack of statistical significance in this study. SDI was calculated using the exponent found by Río et al. [17] for Scots pine stands in Spain $(-1.75)$ instead of the classic Reineke exponent $(-1.605)$. The general forms of the equations in the model are:

$$
\begin{aligned}
d g & =\mathrm{a}_{0} \times N^{\mathrm{a}_{1}} \times H_{0}^{\mathrm{a}_{2}} \\
G & =\mathrm{b}_{0} \times N^{\mathrm{b}_{1}} \times S D I^{\mathrm{b}_{2}} \\
V & =\mathrm{c}_{0} \times S D I^{\mathrm{c}_{1}} \times H_{0}^{\mathrm{c}_{2}}
\end{aligned}
$$

where $a_{i}, b_{i}$ and $c_{i}$ are parameters.

\subsubsection{Parameter estimation}

The coefficients for each equation in the model were estimated using non-linear regression and Marquardt's procedure. As suggested by Ratkowsky [15], parameters from linearization of equations (2), (3) and (4) through the log-log transformation were used as seed values to fit the non-linear parameters.

\subsubsection{Model efficiency}

The efficiency of the model was studied using the following efficiency factor proposed by Soares et al. [19] and Vanclay et al. [23]:

$$
E F=1-\frac{\sum\left(y_{\mathrm{i}}-\hat{y}_{\mathrm{i}}\right)^{2}}{\sum\left(y_{\mathrm{i}}-\bar{y}\right)^{2}} .
$$

An EF value equal to 1 indicates a perfect fit; an $E F$ value equal to zero indicates a fit that is not better than a simple average; and an EF value under zero indicates a fit that is worse than the average.

The signs of the parameters were examined to detect if they were in accordance with present knowledge of forest yield. To examine the predicted values from the model, the relative residual between observed and estimated values was calculated using the formula:

$$
e=\left[\frac{\hat{y}-y_{\mathrm{i}}}{y_{\mathrm{i}}}\right] \times 100 .
$$

Because of the mathematical relationship between $\mathrm{G}$ and $\mathrm{dg}$, the compatibility between equations (2) and (3) was studied by computing an error term in percentage (et). For example, et for basal area is calculated using:

$$
e t=\left[\frac{y_{\mathrm{c}}-y_{\mathrm{i}}}{y_{\mathrm{i}}}\right] \times 100
$$

where $y_{i}$ is the observed value for basal area and $y_{c}$ is computed, using predicted mean quadratic diameter $(\mathrm{dg})$ and the number of stems per hectare $(\mathrm{N})$, as:

$$
y_{\mathrm{c}}=\frac{\pi \times d g^{2} \times N}{4}
$$

In addition predictions from the model were compared with data from permanent plots to further study the model's behavior.

\subsubsection{Model calibration}

An important problem in the application of a growth and yield model is its calibration to different forestry practices or to other geographical zones [6]. Different methods have been proposed to calibrate a forest growth and yield model $[8,13]$. Calibrating a stand to normal yield tables based on the ratio between actual basal area and basal area from the table is routinely used in practice. This method assumes that the model is correct in shape and the calibration is just a scalar modification. This hypothesis may not be true, especially when there are strong differences between the silvicultural treatments in the original stands used to elaborate the model and in the stands where the model is going to be used.

We assume that the actual value of the dependent variable can be expressed by equation (9). In addition, we assume that the calibration factor $(\mathrm{CF})$ is distributed normally. The resulting calibration model used is:

$$
y=f\left(x_{1}, \ldots, x_{n}\right)+\varepsilon+C F
$$

where, $y$ is the observed value of the dependent variable, $f\left(x_{1}, \ldots, x_{n}\right)$ is the predicted value by the equation, $\varepsilon$ is the error of the equation with a mean of zero, and $\mathrm{CF}$ is the calibration factor.

The calibration factor can be a linear or a non-linear function of different variables. These variables can be independent variables in the equation or not. We used a simple linear function for characterizing the calibration factor. The independent variables included in the yield model were checked as variables for the calibration equations. Before developing the calibration equations the behavior of the yield model was first checked using the thinning data set. If the behavior was judged to be good (using the efficiency factor as an index of behavior), the calibration equations would not be developed.

\section{RESULTS}

\subsection{Parameters estimation and goodness-of-fit}

The parameters for each model are given in table I. All the parameters were significant at a 0.05 significance level. In each model, the parameters have the expected sign except for the parameter $b_{1}$ on number of trees per ha in equation (3). However, as in the SDI calculation where we used the total number of trees per ha (regardless of species), the "true" value for the exponent of number of trees per ha in this equation should be positive. No multi-collinearity problems between explanatory variables were detected.

The EF for the validation data set was 0.9546 for the basal area model (Eq. (3)), 0.8301 for the quadratic diameter model (Eq. (2)) and 0.4964 for the volume model (Eq. (4)). These values show that the model form and the independent variables chosen were adequate. Using the validation data set, the volume model (Eq. (4)) underestimated the actual volume when density and dominant height had a high value and overestimated volume otherwise (figure 1).

The relative residuals were usually under $15 \%$, with the highest value $(38.06 \%)$ coming from the basal area equation (figure 2). The largest relative residuals were found in stands with poor site quality (SI = 14).

The check of compatibility between $\mathrm{dg}$ and $\mathrm{G}$ estimators showed that the highest percent errors occured when the mean 
Table I. Parameters estimated for mean quadratic diameter (dg), basal area (G) and volume (V) models for high-graded Scots pine stands in northern Spain.

\begin{tabular}{ccccc}
\hline Model & Parameter & Estimated & $\begin{array}{c}\text { Standard } \\
\text { deviation }\end{array}$ & $\begin{array}{c}\text { Mean squared } \\
\text { error }\end{array}$ \\
\hline $\mathrm{Dg}$ & $\mathrm{a}_{0}$ & 43.791 & 10.898 & 6.655 \\
& $\mathrm{a}_{1}$ & -0.270 & 0.026 & \\
& $\mathrm{a}_{2}$ & 0.426 & 0.056 & \\
\hline $\mathrm{G}$ & $\mathrm{b}_{0}$ & 0.033 & 0.006 & 4.467 \\
& $\mathrm{~b}_{1}$ & -0.107 & 0.023 & \\
\hline $\mathrm{V}$ & $\mathrm{b}_{2}$ & 1.116 & 0.037 & \\
& $\mathrm{c}_{0}$ & 0.168 & 0.052 & 432.674 \\
& $\mathrm{c}_{1}$ & 0.913 & 0.053 & \\
& $\mathrm{c}_{2}$ & 0.413 & 0.065 & \\
\hline
\end{tabular}

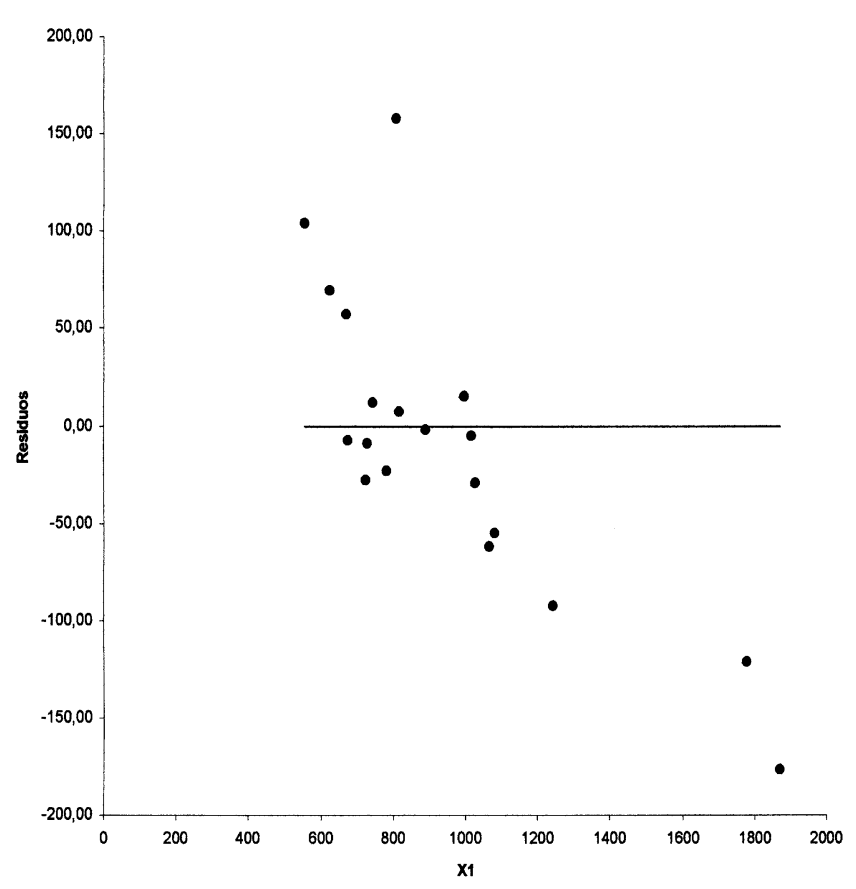

Figure 1. Residuals of the volume model by variable $X_{1}$ using the validation data set. $\left(X_{1}=S D I^{0.913} \times H_{0}^{0.413}\right)$.

quadratic diameter was estimated by the model (Eq. (2)) and basal area was calculated using equation (8) (figure $3 a$ ). So, the basal area model is preferred over the quadratic diameter model (figure $3 b$ ). Comparing predictions from the basal area and volume equations with the actual data from the growth and yield plots, we found that the basal area equation was a better representation of the stand's dynamics than the volume equation. The volume equation overestimated the actual volume when the dominant height is high and underestimates it otherwise (figure 4). This finding is consistent with the comparisons to the validation data set (figure 1) and with the computed EF values.

\subsection{Model calibration}

Because the basal area equation had a high EF value, calculated over the permanent plots data set, and good behavior, only the volume equation was calibrated. Screening the independent variables of the volume model (figure 4) found no relationship between SDI and the calibration factor (Eq. (9)). However, there was a linear relationship between dominant height and the calibration factor. The yield model underestimated the actual volume when the dominant height was smaller than $13.71 \mathrm{~m}$ and overestimated it otherwise. This result agrees with the general high-grading trend, i.e. cut the biggest trees in the tallest stands and avoid cutting in the youngest and in the poorest stands. The following simple linear model (Eq. (10)) was fitted to the calibrating data and the results are shown in table II:

$$
C F=d_{0}+d_{1} \times H_{0}
$$

The adjusted determination coefficient was 0.9169 , the residuals were normally distributed $(P<\mathrm{W}: 0.5332)$ with a mean slightly above zero (0.5077). Using this linear equation, the predicted calibration factor is zero when the dominant height is $13.71 \mathrm{~m}$.

The final volume equation (11) has an EF, calculated over the permanent plots data set, equal to 0.9856 , indicating that its predictions in even-aged stands are more accurate than using the uncalibrated equation.

$$
V=0.168 \times S D I^{0.913} \times H_{0}^{0.413}-215.069+15.685 \times H_{0} .
$$

Comparing yield models with and without calibration factors, we can study the high-grading impact upon forest yield. Equation (4) has been used to simulate high-graded stands, while equation (11) was used to represent standard even-aged silviculture. A medium productivity site (site index $20 \mathrm{~m}$ at 100 years) has been simulated, the flag points were 15,18 and $21 \mathrm{~m}$ in dominant height $(55,75$ and 129 years old). At each of these periods the stand was partially cut, thinned or highgraded, to reduce the SDI from 1000 to 700, assuming that, on average, one meter increment in dominant height represents an increment of 100 points in SDI [16]. The standing volume reduction due to high-grading at 129 years is over $26 \%$ while the total volume reduction is $18 \%$. At 75 years of age the reduction is over $18 \%$ of standing volume and almost $15 \%$ of total volume (table III).

\section{DISCUSSION}

In this study, data from a single measurement of permanent plots were analyzed to develop a yield model for high-graded stands. Therefore, continuing studies are needed using repeated measurements from these plots to fully understand the influence of high-grading on forest stand dynamics. Some modifications of the model would be necessary to study the impact of hardwoods on Scots pine yield. Nonetheless, the yield model developed in this study allows, in combination with the appropriate site index curves, to adequately forecast the yield of previously high-graded Scots pine stands in northern Spain. 

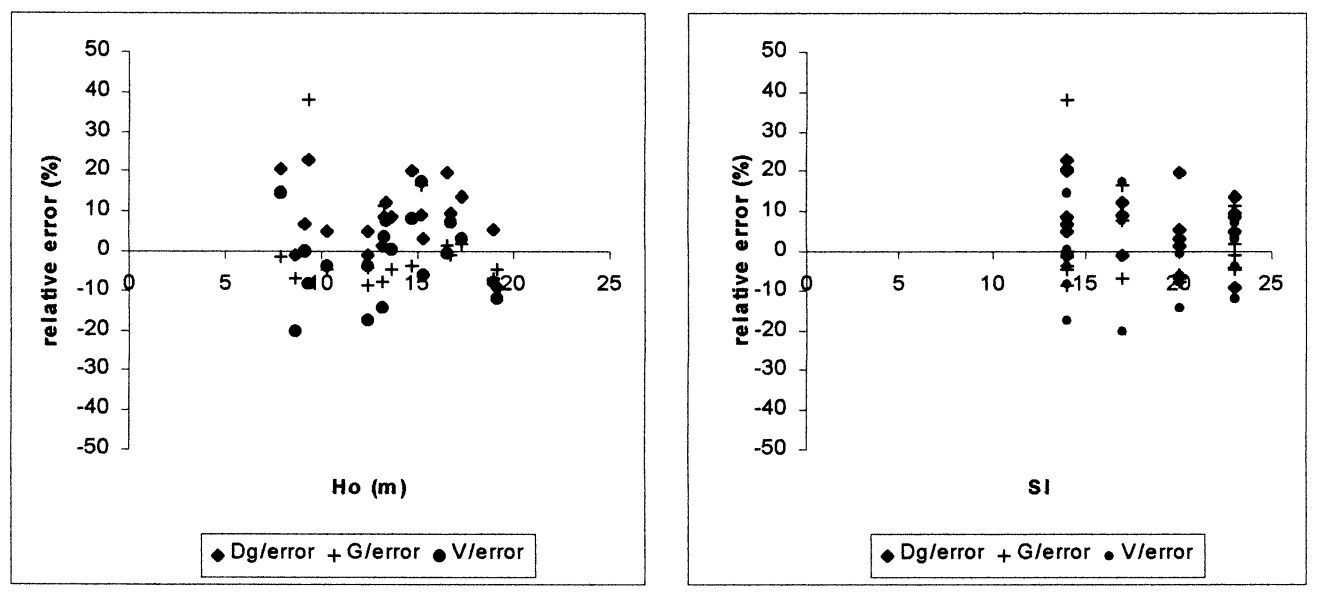

Figure 2. Error rates of mean quadratic diameter, basal area and volume models by dominant height (a) and SDI (b) in high-graded Scots pine stands in northern Spain.

Table II. Analysis of variance for the simple linear model of calibration factor for high-graded Scots pine stands in northern Spain.

\begin{tabular}{|c|c|c|c|c|}
\hline Source & Degree of freedom & Squared sum & Mean squared & $\overline{\text { Prob }>\text { F }}$ \\
\hline Model & 1 & 61026.351 & 61026.351 & 0.0001 \\
\hline Error & 80 & 5457.157 & 68.214 & \\
\hline Total & 81 & 66483.489 & & \\
\hline Parameter & Estimated & Standard deviation & t for Ho: $\beta=\mathbf{0}$ & \begin{tabular}{l|l} 
Prob $>$ & $t$
\end{tabular} \\
\hline $\mathrm{d}_{0}$ & -215.069 & 7.254 & -29.647 & 0.0001 \\
\hline $\mathrm{d}_{1}$ & 15.685 & 0.524 & 29.910 & 0.0001 \\
\hline
\end{tabular}

Table III. Total and standing volume in a medium productivity (site index $20 \mathrm{~m}$ at 100 years), high-graded and non high-graded Scots pine stands in northern Spain.

\begin{tabular}{lcccccrc}
\hline & & \multicolumn{2}{c}{ Standing volume (cubic meters) } & \multicolumn{2}{c}{ Total volume (cubic meters) } \\
\hline $\begin{array}{l}\mathbf{H}_{\mathbf{0}} \\
(\mathbf{m})\end{array}$ & $\begin{array}{c}\text { Age } \\
\text { (year) }\end{array}$ & High-graded & $\begin{array}{c}\text { Non } \\
\text { high-graded }\end{array}$ & $\begin{array}{c}\text { Reduction } \\
\text { (percent) }\end{array}$ & High-graded & $\begin{array}{c}\text { Non } \\
\text { high-graded }\end{array}$ & $\begin{array}{c}\text { Reduction } \\
\text { (percent) }\end{array}$ \\
\hline 15 & 55 & 281.86 & 302.07 & 6.69 & 281.86 & 302.07 & 6.69 \\
18 & 75 & 303.90 & 371.17 & 18.12 & 382.24 & 449.51 & 14.96 \\
21 & 129 & 323.88 & 438.20 & 26.09 & 492.81 & 601.00 & 18.00 \\
\hline
\end{tabular}

Dominant height shows a key influence upon high-graded stands evolution. The residual overstory density has a strong influence upon residual tree height growth [11]. From the data of Spanish National Inventory studied we can not know the residual overstory density and, in addition, our permanent plots data set unfortunately do not provide any information about residual overstory density. However, height is the calibrated variable in our model showing its importance on tree's response to high grading practices. Both age and site index can be expressed by dominant height to some extent. The ability to predict growth variation in even-aged stands is low when both age and site quality are eliminated, however even-aged stand structure is uncommon in high-graded stands.

The calibration factor function improved the volume model estimations in even-aged stands. The linear relationships between the calibration factor and dominant height shows the impact of a high-grading practice that removes the overstory.
The gaps created by high-grading are occupied by some young trees, so the basal area model does not need calibration. The reduction in volume we found agree with other studies in Mediterranean pines in stands showing a high structural diversity [1]. As high grading promotes structural diversity both in diameter (figure 5) and height, a yield reduction must be expected.

Other modeling strategies such as individual tree model (ITM), would be better models for our purpose than whole yield stand model. The Forest Vegetation Simulator [22] developed by the US Forest Service or the Oregon Growth and Yield Model (ORGANON) supported by the forestry program at Oregon State University [7] in North America and PROGNAUS (the Austrian variant of PROGNOSIS) which was implemented by Sterba and collaborators [20, 21] in Europe are good example of ITMs that are useful for evaluating silvicultural treatments such as high-grading. However, no data are available in our targeted stands to develop this kind of model 

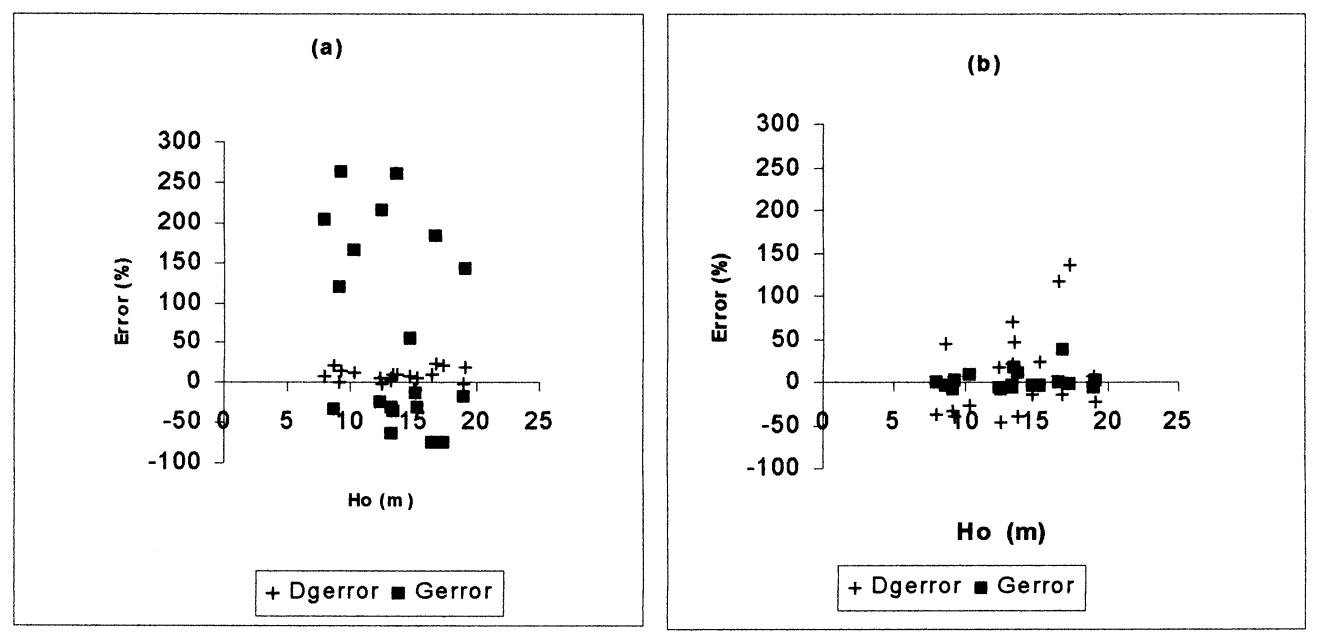

Figure 3. Error rates estimated dg by the model and calculating G (a) and estimating G and calculating dg (b) by dominant height in highgraded Scots pine stands in northern Spain.
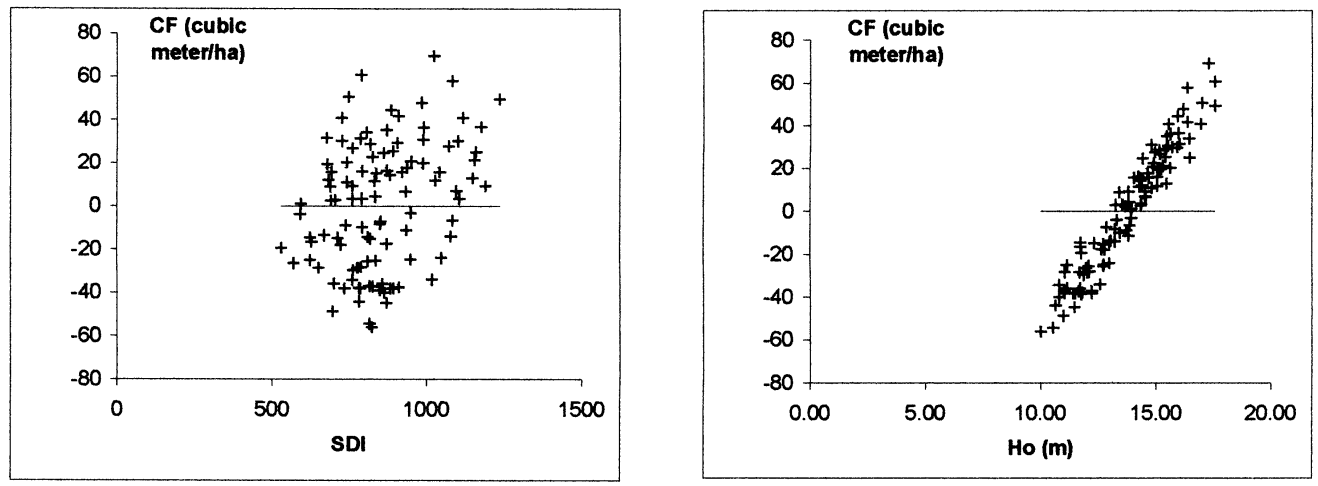

Figure 4. Plot of the calibration factor by SDI and $\mathrm{H}_{0}$ for the volume model for high-grading Scots pine stands in northern Spain. $\mathrm{CF}$ is the calibration factor.

so our modeling approach is the only one possible in such a situation (one yield measurement and no increment records). On the other hand, this situation (lack of a strong data set to develop ITMs) is very common around the world and foresters need some kind of orientation to develop their silvicultural strategies in practice. A whole yield model plus an adequate calibration function can serve as a guide for practicing foresters while new models are developed.

Although, as far as we know, there is no literature dealing with economic implications of high-grading, it is clear that the possible financial gain in the first years of a rotation by applying high-grading is surpassed by the problems created in the long run, such as structurally non-equilibrated stands or technologically low-quality standing trees. However, when forest management is oriented to develop structurally complex stands (i.e., in Green Tree Retention practices), costs in terms of timber production and management complexity must be balanced with the gain in other features such as biological diversity or aesthetic considerations. In the climatic transitional area in northern Spain, old high-grading practices allow beech to invade originally pure Scots pine stands improving its aesthetic value. A new growth and yield modeling strategy using individual distance-independent models would be beneficial for modeling these types of stands. The implications of high grading on reduction of timber production have been stated. This result should be used as foundation to avoid high grading in forestry elsewhere and especially in areas where timber production is a well-stated goal. If the goal is promote structural diversity, other silvicultural strategies must be explored. 

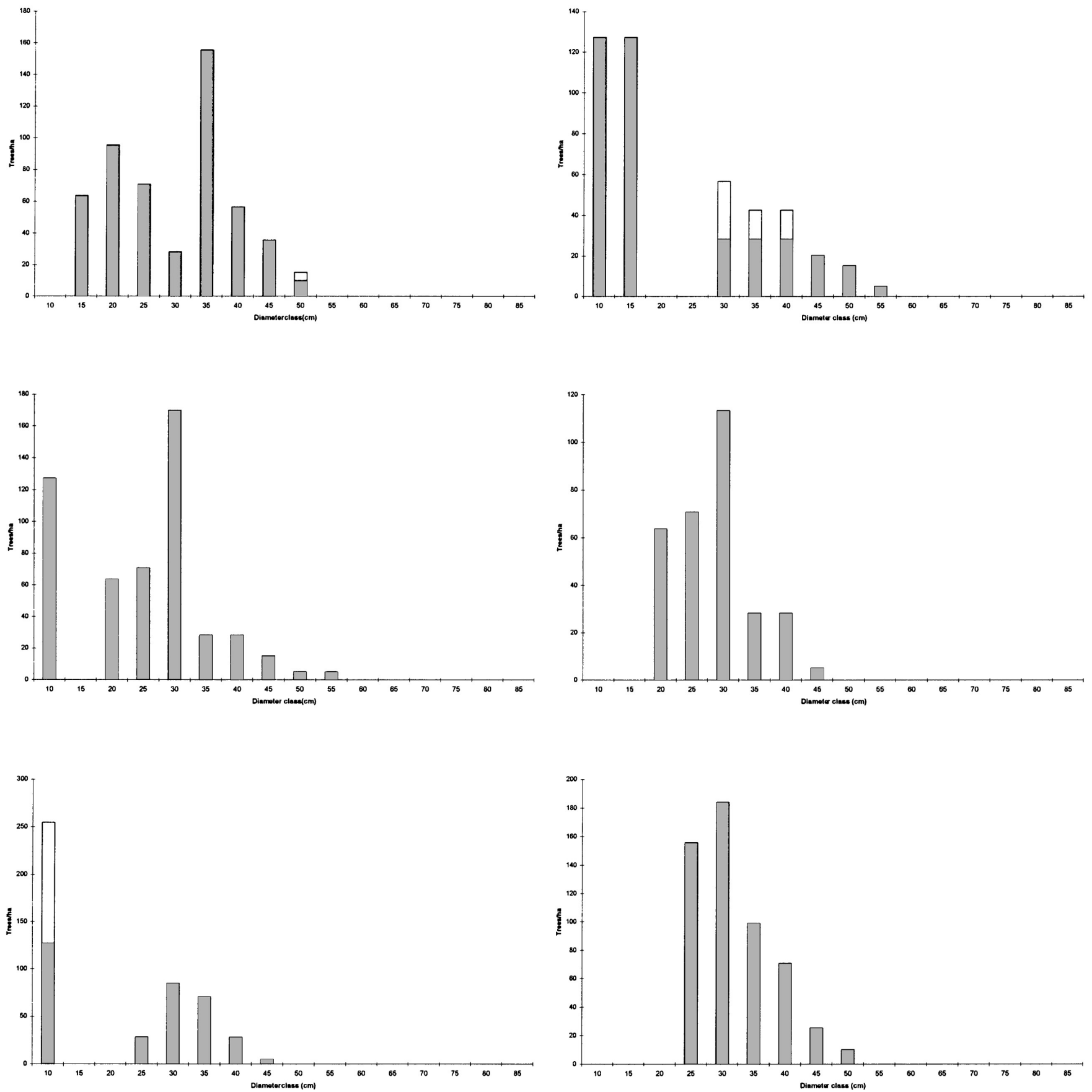

Figure 5. Diameter distributions of some examples of Scots pine high graded stands in High Ebro Basin (northern Spain). Shadow: Scots pine stems per hectare, white: other species (mostly beech) stems per hectare.

Acknowledgements: The authors wish to thank A. Picardo for his encouragement, S. González, N. Nanos, D. Hann and two anonymous referees for their comments that improved the manuscript, R. Jackson who checked the English version and A. Bravo who helped in the field work.

\section{REFERENCES}

[1] Bravo F., Guerra B., Forest structure and diameter growth in Maritime pine in a Mediterranean area, in: von Gadow K., Nagel J., Saborowski J. (Eds.), Continuous Cover Forestry IUFRO meeting, 2001, pp. 101-110. 
[2] Bravo F., Montero G., Site index estimation in Scots pine (Pinus sylvestris L.) stands in the High Ebro Basin (northern Spain) using soil attributes, Forestry 74 (2001) 395-406.

[3] Eriksson H., Yield of Norway Spruce in Sweden. Dept. of Forest Yield Rap. No 41, 1976.

[4] González-Martínez S.C., Bravo F., Density and population structure of the natural regeneration of Scots pine (Pinus sylvestris L.) in the High Ebro Basin (Northern Spain), Ann. For. Sci. 58 (2001) 277-288.

[5] ICONA, Segundo Inventario Forestal Nacional. Explicaciones y métodos. Madrid, 1990.

[6] Krumland B.E., A tree-based forest yield projection system for the North Coast region of California. Ph.D. Thesis, unpublished, U. California, Berkeley, 1982.

[7] Hann D.W., Hester A.S., Olsen C.L., ORGANON user's manual: Edition 6.0. Department of Forest Resources, Oregon State University, Corvallis, OR, 1997, 133 p.

[8] Lappi J., Calibration of height and volume equations with random parameters, For. Sci. 37 (1991) 781-801.

[9] Larson B., Development and growth of even-aged stands of Douglas-fir and grand fir, Can. J. For. Res. 13 (1986) 367-372.

[10] Lu H.-C., Buongiorno J., Long- and short-term effects of alternative cutting regimes on economic returns and ecological diversity in mixed-species forests, For. Ecol. Manage. 58 (1993) 173-192.

[11] Murphy T.E., Adams D.L., Ferguson O.E., Reponse of advance lodgepole pine regeneration to overstory removal in eastern Idaho, For. Ecol. Manage. 120 (1999) 235-244.

[12] Oliver C.D., Larson B.C., Forest Stand Dynamics, John Wiley and Sons, New York, 1996.
[13] Payandeh B., Papadopol P., Partial calibration of 'ONTWIGS': A forest growth and yield projection system adapted for Ontario, North. J. Appl. Forest. 11 (1994) 41-46.

[14] Persson O.A., A growth simulator for Scots pine (Pinus sylvestris L.) in Sweden. Dept. of Forest Yield-SLU Rap. No 31, 1992.

[15] Ratkowsky D.A., Nonlinear regression modeling. A unified approach, Marcel Dekker, Inc., New York, 1983.

[16] Río M. del, Régimen de claras y modelo de producción para Pinus sylvestris L. en los sistemas Central e Ibérico. Ph.D. Thesis, ETSIM-UPM, 1998.

[17] Río M. del, Montero G., Bravo F., Analysis of diameter-density relationships and self-thinning in non-thinned even-aged Scots pine stands, For. Ecol. Manage. 142 (2001) 79-87.

[18] Rojo A., Montero G., El pino silvestre en la Sierra de Guadarrama MAPA, Madrid, 1996.

[19] Soares P., Tome M., Skovsgaard J.P., Vanclay J.K., Evaluating a growth model for forest management using continuous forest inventory data, For. Ecol. Manage. 71 (1995) 215-265.

[20] Sterba H., Monserud R.A., Validation of the single tree stand growth simulator PROGNAUS with permanent plot data, Proceedings of the Meeting of IUFRO S4.11-00 at IUFRO XX World Congress, 6-12 August 1995, Tampere, Finland, 1996, pp. 36-49.

[21] Sterba H., Monserud R.A., Applicability of the forest stand growth simulator PROGNAUS for the Austrian part of the Bohemian Massif, Ecol. Model. 98 (1997) 23-34.

[22] USDA, FVS, the forest vegetation simulator, 2000.

[23] Vanclay J.K., Skovsgaard J.P., Garcia O., Evaluating forest growth models, Proc. of Meeting of IUFRO S4.11.00, IUFRO XX World Congress, Tampere, Finland, 1996, pp. 11-22. 